\title{
Liquid Chromatography Analysis of Reactive Oxoammonium Cations
}

\author{
Philip Rohland ${ }^{1,2} \cdot$ Kristin Schreyer $^{1,2} \cdot$ Rene Burges $^{1,2} \cdot$ Nicole Fritz $^{1,3} \cdot$ Martin D. Hager $^{1,2} \cdot$ Ulrich S. Schubert $^{1,2}$ (I)
}

Received: 11 March 2021 / Revised: 6 May 2021 / Accepted: 18 August 2021 / Published online: 7 September 2021

(c) The Author(s) 2021

\begin{abstract}
This study presents the first liquid chromatography method for the quantitative and qualitative analysis of highly reactive oxoammonium cations based on a simple derivatization reaction. Rapid 1,2-electrophilic addition reactions with olefins were used to transform these reactive species into analyzable derivates. Three model substances were chosen to represent each of the main application fields of oxoammonium cations and to demonstrate the versatility of the method. The measuring protocol was validated according to the ICH and USP guidelines. The method revealed an excellent linearity $\left(R^{2}=0.9980-0.9990\right)$ with a low limit of detection $\left(0.16-0.14 \mathrm{mmol} \mathrm{L}^{-1}\right)$ and a low limit of quantification $\left(0.55-0.43 \mathrm{mmol} \mathrm{L}^{-1}\right)$. The protocol was finally used to determine the oxoammonium cations in the presence of their corresponding radical, showing a robustness against impurity concentration of up to approx. $30 \%$.
\end{abstract}

Keywords LC $\cdot$ LC-MS $\cdot$ Highly reactive analytes $\cdot$ Oxoammonium cations $\cdot$ Derivatization protocol

\section{Introduction}

Despite the fact that 2,2,6,6-tetramethylpiperidinyloxyl (TEMPO)-based oxoammonium cations (OCs) play an important role in many current developments, like green oxidation chemistry or organic energy storage, they are fairly unheeded. Their most outstanding property is their stable and reversible redox behavior (Fig. 1) involving the oxoammonium cation 1 and the corresponding aminoxyl radical 2. Another redox reaction, between the radical 2 and the hydroxylamine $\mathbf{3}$, is possible but the $\mathrm{pH}$-dependency of this step is limiting the application possibilities [1].

The reversible redox reactions of OCs are frequently used in organic synthesis to oxidize primary or secondary alcohols to the corresponding aldehydes/ketones or even carboxylic acids $[2,3]$. The oxoammonium cation can act as

Ulrich S. Schubert

ulrich.schubert@uni-jena.de

1 Laboratory of Organic and Macromolecular Chemistry (IOMC), Friedrich Schiller University Jena, Humboldtstraße 10, 07743 Jena, Germany

2 Center for Energy and Environmental Chemistry Jena (CEEC Jena), Friedrich Schiller University Jena, Philosophenweg 7a, 07743 Jena, Germany

3 Jena Center for Soft Matter (JCSM), Friedrich Schiller University Jena, Philosophenweg 7, 07743 Jena, Germany the oxidant itself or as oxidation catalyst in connection with cost-efficient inorganic oxidants like sodium hypochlorite or oxygen, offering a sustainable and green way to produce aldehydes, ketones, and carboxylic acids from alcohols [4-6]. Further fields of application are electrochemical energy storage, with the oxoammonium-aminoxyl redox couple as one of the best investigated systems with regard to organic batteries [7-9], and biological and pharmaceutical applications of the oxoammonium cation, e.g., as antihypertensives or pro-oxidants [10-12].

Despite the broad application possibilities of OCs, the analytical methods for this species are rather limited. While many of their corresponding hydroxylamines and radicals can be identified and quantified using standard methods, like ESR, NMR, titration, or MS, even the qualitative analysis of the oxidized state is difficult [8,13-15]. On the one hand, oxoammonium cations, in general, are prone to decomposition reactions and possess only a limited lifetime [16]. On the other hand, there are also method-specific drawbacks. Small amounts of radical disturb NMR measurements and ESR is neither sensitive nor sufficient accurate to quantify radical impurities to draw conclusions on cation purity [17, 18]. Furthermore, the IR or UV/Vis spectra of the radical and the oxoammonium cation are in many cases too similar for proper analysis [19-22]. A simple evaluation utilizing the increase or decrease of specific bands is thus often not suitable. However, more advanced techniques like near-infrared 


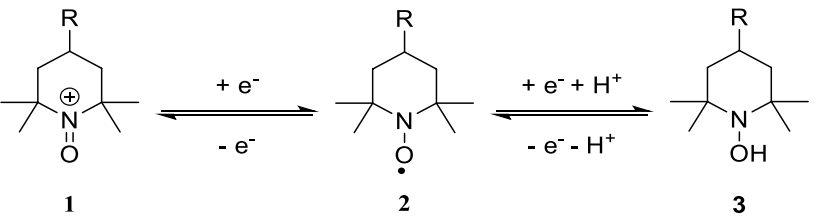

Fig. 1 Schematic representation of the redox chemistry of TEMPObased molecules

spectroscopy in combination with chemometrics might overcome the problems [23-25]. MS techniques are suitable in terms of accuracy and sensitivity but the discrimination between the two redox species is not sufficient. Furthermore, the radical is oxidized to the corresponding oxoammonium cation under MS conditions[26] and the commonly used steel parts in HPLC and GC systems can reduce the oxoammonium cation to the radical form due to its high oxidation potential [8]. To circumvent the stated drawbacks, a derivatization reaction that transforms the oxoammonium cation into a less reactive and more distinguishable species is highly desirable.

In 1999, Takata and co-workers showed that oxoammonium cations can undergo fast 1,2-electrophilic additions with olefins under excellent yields [27]. But the derivates were not stable, even at $-20^{\circ} \mathrm{C}$. We used the reaction introduced by Takata et al. as the starting point for our derivatization method (Fig. 2). We could improve the reaction conditions by optimization and could apply the new protocol to three different oxoammonium cations. Namely, the Bobbitt salt ( $N$-(2,2,6,6-tetramethyl-1-oxopiperidin-1-ium4-yl)acetamide tetrafluoroborate) (4), the TMA-TEMPO (2,2,6,6-tetramethyl-1-oxo-4-(trimethylammonium)piperidin-1-ium dichloride) OC (5), and the TEMPOL (4-hydroxy2,2,6,6-tetramethyl-1-oxopiperidin-1-ium chloride) OC (6) were chosen as model substances for oxidation catalysts, organic radical batteries, and pharmaceutical applications, respectively, due to their wide spread in their respective fields (Fig. 2). We report that the standard solutions of the derivatives lose only approx. $0.5 \% \mathrm{~d}^{-1}$ over 12 days at $5{ }^{\circ} \mathrm{C}$. We then demonstrated a valid derivatization-based liquidchromatography method for separation, identification, and quantification of the oxoammonium cations, even in presence of the corresponding radical species.

\section{Materials, Methods and Instruments}

\section{Chemicals and Reagents}

Sodium chloride ( $\geq 99.5 \%$, Fisher Scientific Ltd., United Kingdom), TEMPOL (ABCR GmbH, Germany), 4-acetylamino-2,2,6,6-tetramethyl-1-piperidinoxy (TCI, Japan),
( $N$-(2,2,6,6-tetramethyl-1-oxopiperidin-1-ium-4-yl)acetamide tetrafluoroborate (TCI, Japan), tetramethyl urea (TMU) (TCI Chemicals, Japan), mesitylene (VWR International GmbH, Germany), acetonitrile (HiPerSolv CHROMANORM®, VWR International GmbH, Germany), water (HiPerSolv CHROMANORM®, VWR International GmbH, Germany), formic acid (HPLC LiChropur, Sigma Aldrich, USA), $N$-vinylcarbazole (Sigma Aldrich, USA) and ESI-L Low Concentration Tuning Mix (Agilent Technologies, USA) were purchased and used without further purification. TMA-TEMPO and methyl viologen were synthesized according to literature procedure [8].

\section{Instrumentation}

An UltiMate 3000 HPLC system equipped with a DAD (Thermo Scientific, USA) was used for separation, identification and quantification of the three derivatization products as well as the internal standard. For data processing the Chromeleon 7.2 software was used.

For assignment of the DAD signals, LC-MS measurements were performed utilizing a Series 1200 HPLC (Agilent Technologies, USA) equipped with a micrOTOF QII mass spectrometer (Bruker, Germany) and a DAD. Ions were generated using the electrospray ionization source (ESI) and a measurement range between $\mathrm{m} / \mathrm{z} 280$ and 3000 was used. The MS-data were evaluated with the Bruker Data Analysis software version 4.2 and the HPLC data were analyzed with the HyStar 3.2 software.

Weighing was done on an XS205 Dual Range balance (Mettler Toledo, USA).

\section{Chromatographic Conditions}

The HPLC separation was done with a C18 column (Kinetex EVO C18, $150 \mathrm{~mm} \times 4.6 \mathrm{~mm}, 5 \mu \mathrm{m}$, Phenomenex, Germany) using a gradient program with two mobile phases A and B. The mobile phase A is acetonitrile with 0.1 vol.\% formic acid and the mobile phase B is pure water with $0.1 \mathrm{vol} . \%$ formic acid. The flow rate was set to $1.5 \mathrm{~mL} \mathrm{~min}^{-1}$ and the gradient was programmed as: Time $(\mathrm{min}) / \mathrm{B}(\%)$ : 0.0/85.0, 11.0/40.0, 12.0/40.0, 14.0/5.0, 16.0/5.0, 17.0/85.0 and 22.0/85.0. The column temperature was maintained at $40{ }^{\circ} \mathrm{C}$ and the auto-sampler temperature was set to $5{ }^{\circ} \mathrm{C}$. The injected volume of the sample solutions was $10 \mu \mathrm{L}$. The absorbance was monitored using a DAD-detector.

The same conditions, mobile phase, injected volume and column was used for LC analytics with subsequent MS. The gradient program was extended to $27 \mathrm{~min}$ and programmed as: time $(\mathrm{min}) / \mathrm{B}(\%): 0.0 / 85.0,11.0 / 40.0$, $12.0 / 40.0,14.0 / 5.0,16.0 / 5.0,17.0 / 85.0$ and $27.0 / 85.0$ and 
Fig. 2 Schematic representation of the derivatization reaction of the Bobbitt salt (4), TMATEMPO OC (5) and TEMPOL OC (6) to the corresponding analyzable derivatives

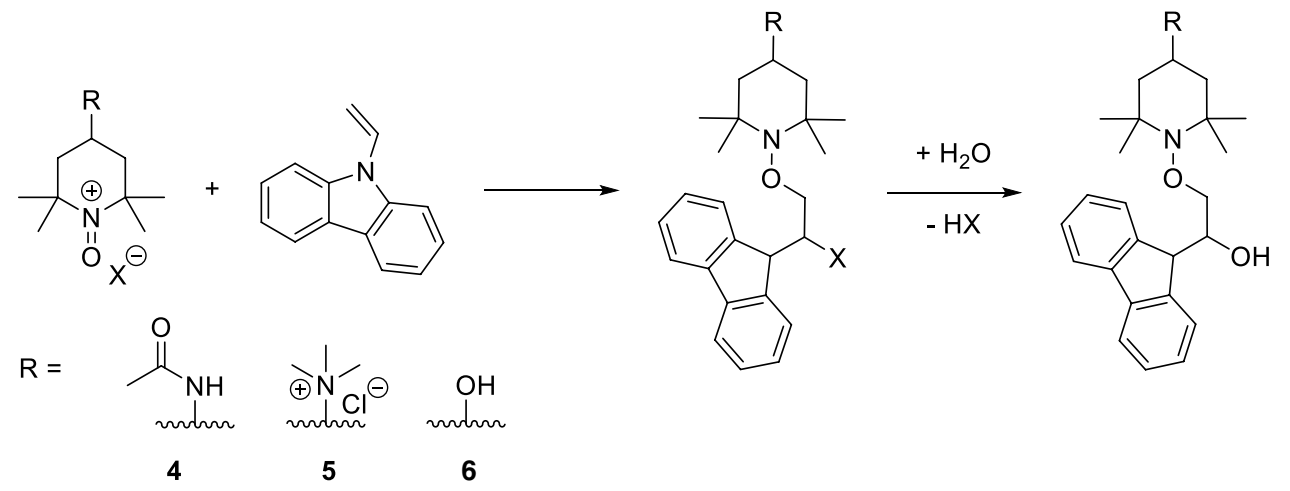

the auto-sampler temperature was room temperature. The split to the MS was measured as $1 / 3$.

\section{Derivatization Method and Sample Preparation}

\section{Stock Solution}

Stock solutions of $0.1 \mathrm{M}$ oxoammonium cations with $0.1 \mathrm{M}$ sodium chloride in water were prepared. While the Bobbitt salt was used directly, for TEMPOL OC and TMA-TEMPO $\mathrm{OC}$, the radicals were used and, subsequently, electrochemically oxidized in a redox flow battery (details in the supporting information). The stock solutions were stored at $4{ }^{\circ} \mathrm{C}$ until usage.

\section{Sample Preparation for Stability Test}

Samples of $1 \mathrm{~mL}$ for the stability tests were prepared from the oxoammonium stock solutions and a $0.1 \mathrm{M} \mathrm{N}$-vinylcarbazole TMU solution, as well as $100 \mu \mathrm{L}$ of a $83 \mathrm{mmol} \mathrm{L}^{-1}$ (10 $\mathrm{mg} \mathrm{mL}^{-1}$ ) mesitylene solution in TMU as internal standard. The amounts of the components were chosen to fit the respective targeted OC concentration ( $c f$. "Results and Discussion"), with a ratio of the derivatization reagent $N$-vinylcarbazole to the analyte of $2: 1$. The resulting mixture was diluted with TMU to $1 \mathrm{~mL}$ and injected into the chromatographic system.

\section{Standard Sample Preparation}

The samples were prepared as described for the stability tests, but they were homogenized for $3 \mathrm{~min}$ with a vortexer (Vortex Genie 2, Scientific Industries, USA) prior to injection into the chromatographic system.

\section{Sample Preparation for LC-MS Measurements}

The samples were prepared as described for the standard sample preparation. But before injection into the chromatographic system, the probes were diluted with TMU to $0.1 \mathrm{mg} \mathrm{mL}^{-1}$ for the Bobbitt salt and TEMPOL OC and to $0.01 \mathrm{mg} \mathrm{mL}^{-1}$ for the TMA-TEMPO OC sample.

\section{Results and Discussion}

Aminoxyl radicals can be oxidized to their corresponding oxoammonium cations either by utilizing oxidizing mineral acids, like perchloric acid [28] and sulfuric acid [29], or other strong oxidants like hypochlorites [30, 31]. But these procedures require additional purification steps to remove potentially disturbing side products. Furthermore, some of these techniques do not tolerate specific organic functional moieties, e.g., the hydroxyl group of TEMPOL can react with sulfuric acid to form an ester [9]. Thus, we decided to use the mild electrochemical oxidation as analyte solution preparation procedure since the received oxoammonium cation solution can be directly used without further purification.

\section{Stability of the Analyte}

Takata et al. stated that the addition products of oxoammonium cations and olefins are rather unstable [27]. We thus wanted to investigate if the derivatization protocol of Takata et al. can be used for the named oxoammonium cations. For proper solubility, the utilized chloroform must be exchanged with a 1:3 (v:v) mixture of water and acetonitrile. The stability of the TMA-TEMPO derivative was subsequently investigated using ${ }^{1} \mathrm{H}$ NMR spectroscopy. Herein, freshly prepared analyte samples were placed inside the NMR spectrometer with a pre-tempered probe head (5, $10,15,25,40{ }^{\circ} \mathrm{C}$ ) for $480 \mathrm{~min}$ and every $5 \mathrm{~min}$ a spectrum was recorded ( $c f$. SI for detailed analysis procedure and all data). The results revealed that the decomposition rates of 
$17.1 \% \mathrm{~d}^{-1}$ at $5^{\circ} \mathrm{C}$ and $99.9 \% \mathrm{~d}^{-1}$ at $40{ }^{\circ} \mathrm{C}$ are much too high for HPLC analysis.

Consequently, we exchanged the used solvent mixture with tetramethyl urea (TMU). On the one hand, it is capable of dissolving even double-charged oxoammonium cations as well as the nonpolar internal standard mesitylene. On the other hand, TMU is not nucleophilic and can act as base and binds (possibly) formed acids, which would lead to analyte decomposition via carbazole cleavage. To investigate the impact of the solvent on the stability of the addition products, we prepared three different samples for each of three different concentrations $\left(35,28,21 \mathrm{mmol} \mathrm{L}^{-1}\right)$ for each cation. The samples were kept in the auto-sampler at $5{ }^{\circ} \mathrm{C}$ for 12 days, and one measurement per day was carried out for each sample.

We wanted to eliminate variations due to sample preparation using the internal standard calibration method. While the ratios of the analyte and internal standard signals differ by up to $40 \%$ among the three samples for each concentration, they stay nearly constant over the time of the experiment showing a small trend of decrease. The high differences among the samples with the same concentration might be linked to difficulties during the preparation of the standard solution and possible problems during homogenization of the mixture. The challenge of changing concentrations because of diffusion and osmosis in the RFB is discussed below. The slow decrease of the analyte signal over time can be correlated to the decomposition of the analyte. However, with approx. $0.5-1.0 \% \mathrm{~d}^{-1}$ for the three different concentrations for the different oxoammonium cations, the decay is reduced to approx. one twentieth in comparison to initial derivatization procedure.

\section{Analyte and Side Product Identification}

The assignment of the DAD signals (Fig. 3) was done by mass spectrometry (see supporting information Figure S8-S10).

\section{Method Transfer}

For method transfer, the retention time of the analyte and the internal standard were determined on the LC-MS as well as on the LC system. The differences of around $0.6 \mathrm{~min}$ between the LC-MS and the $\mathrm{LC}$ are due to the increased path length in the chromatographic system of the LC-MS.

\section{Method Validation}

The developed method was validated according to ICH and USP Guide lines [32,33]. This includes a system suitability test and the determination of validation parameters like specificity, linearity, accuracy, and precision.
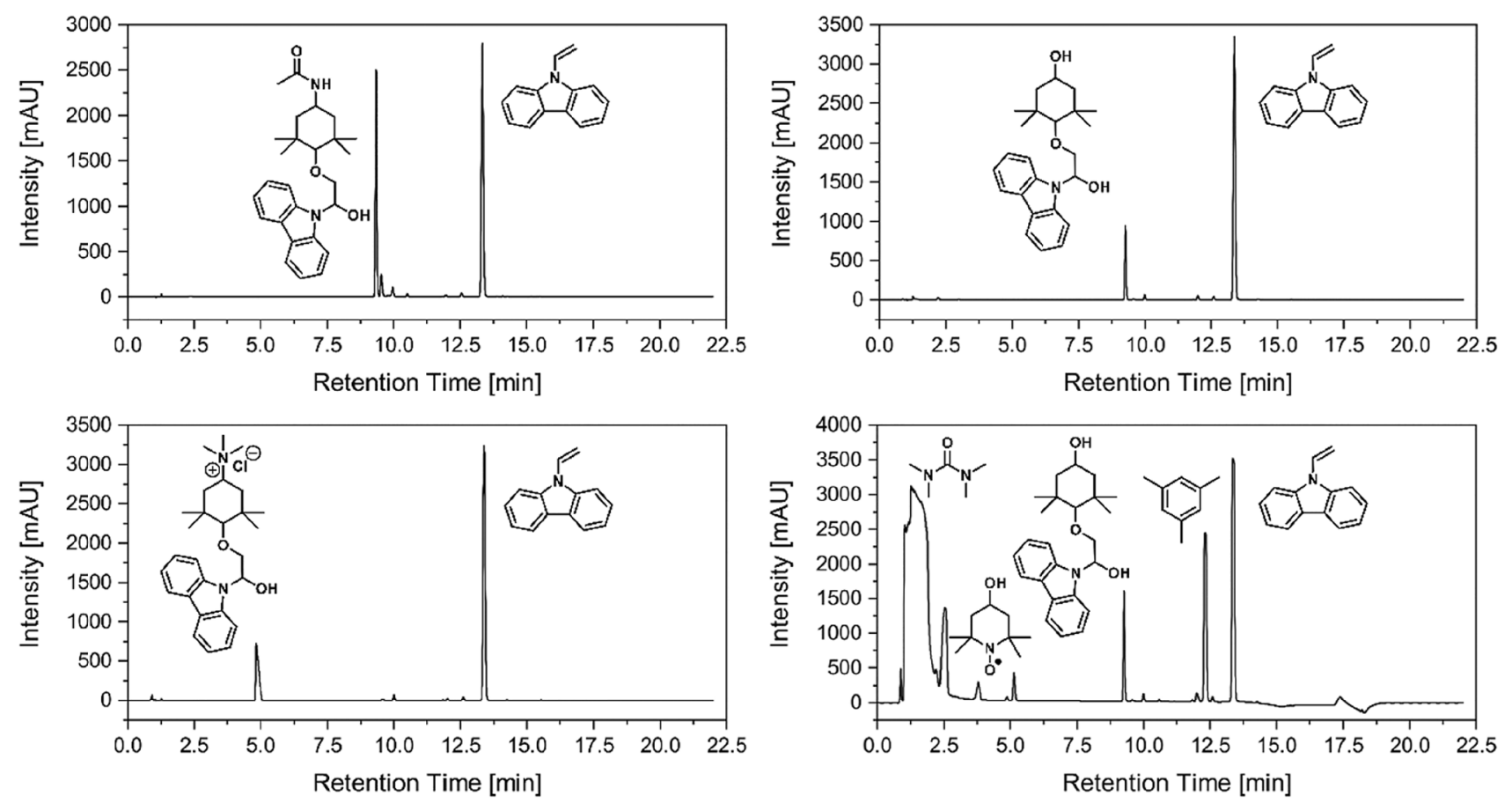

Fig. 3 Typical UV-chromatogram at $291 \mathrm{~nm}$ of the $N$-vinylcarbazole adducts of the Bobbitt salt (upper left), TEMPOL OC (upper right), TMATEMPO OC (lower left) and the UV-chromatogram at $209 \mathrm{~nm}$ of the adduct of the TEMPOL-OC (lower right) 


\section{System Suitability Test}

After optimizing the sample preparation process (longer homogenization process), system suitability parameters were determined and compared to USP guidelines [34]. The parameters include resolution, plate count, capacity factor, tailing factor, and relative standard deviation (RSD) of the peak areas. To determine the parameters, the data from six replicate injections of solutions with a concentration of $30 \mathrm{mmol} \mathrm{L}^{-1}$ were used. The parameters are summarized in Table 1. In general, the parameters fulfill the requirements of the guidelines. An exception is the resolution of the Bobbitt salt, which is a little bit too low with 1.87 (required to be higher than 2) but the peak overlap is so narrow that it is considered as not crucial. Furthermore, the tailing factor of the TMA-TEMPO OC is too high (should be $\leq 2$ ), but it was considered acceptable because of the high resolution. Overall, the system suitability test was considered as successful.

\section{Specificity}

To determine the specificity of the method, the resolutions of the OC signals in a mixture with typical synthesis side products and decomposition products need to be investigated. For this purpose, the studied compounds were either commercially available synthesis-grade or self-synthesized chemicals. In both cases, the main side products and impurities are inherently included in the samples, rendering them suitable for specificity tests. The thus performed studies showed no interferences of the OC signals and resolutions higher than 1.5 for all chromatograms (see Supporting Information).

\section{Linearity and Range}

The linearity was determined using calibration samples with analyte concentrations of $14,21,24,28$, and $35 \mathrm{mmol} \mathrm{L}^{-1}$. For every concentration, six replicates were prepared and injected once per replicate. The received ratios of the peak areas of the analyte and the peak areas of the internal standard were plotted against the respective concentrations. The calibration curves were determined by the least-squares linear regression analysis and showed linear behavior in the whole studied range from 14 to $35 \mathrm{mmol} \mathrm{L}^{-1}$ with a determination coefficient $\left(R^{2}\right)$ of 0.9980 to 0.9990 . The limits of detection (LOD) and the limits of quantification (LOQ) were calculated using the following formula [33]:

$\mathrm{LOD}=\frac{3.3 \sigma}{S}$

$\mathrm{LOQ}=\frac{10 \sigma}{S}$

$\sigma=$ standard deviation of y-intercept of regression lines, $S=$ slope of the calibration curve.

The results of the linearity studies are summarized in Table 2.
Table 1 Results of the system suitability test $(n=6)$

\begin{tabular}{llllcl}
\hline Parameter & Bobbitt salt & $\begin{array}{l}\text { TMA- } \\
\text { TEMPO } \\
\text { OC }\end{array}$ & TEMPOL OC & Internal standard & $\begin{array}{l}\text { Required } \\
\text { according to } \\
\text { USP }\end{array}$ \\
\hline Resolution $\left(R_{s}\right)$ & 1.87 & 24.52 & 2.64 & 6.25 & $>2$ \\
Plate count $(N)$ & 130,903 & 5773 & 127,494 & 64,575 & $>2000$ \\
Capacity factor $(k)$ & 9.82 & 4.61 & 9.72 & 13.23 & $>2$ \\
Tailing factor $(T)$ & 1.08 & 3.58 & 1.04 & 1.09 & $\leq 2$ \\
\% RSD (peak area) & 0.27 & 0.16 & 0.20 & 0.18 & $\leq 1$ \\
\hline
\end{tabular}

Table 2 Data of the linearity study

\begin{tabular}{llll}
\hline & Bobbitt salt & TMA-TEMPO OC & TEMPOL OC \\
\hline Range $\left(\mathrm{mmol} \mathrm{L}^{-1}\right)$ & $14-35$ & $14-35$ & $14-35$ \\
Determination coefficient $\left(R^{2}\right)$ & 0.9990 & 0.9985 & 0.9980 \\
Slope of the calibration curve $(S) \mathrm{mmol}^{-1} \mathrm{~L}$ & 175.5695 & 142.7708 & 68.4183 \\
Intercept & -0.0068 & -0.0973 & -0.0299 \\
Standard deviation of the slope $(\sigma)$ & 4.6347 & 3.1944 & 1.7834 \\
Standard deviation of y-intercept $(\sigma)$ & 0.0075 & 0.0068 & 0.0037 \\
LOD $\left(\mathrm{mmol} \mathrm{L}^{-1}\right)$ & 0.13 & 0.14 & 0.16 \\
LOQ $\left(\mathrm{mmol} \mathrm{L}^{-1}\right)$ & 0.43 & 0.47 & 0.55 \\
\hline
\end{tabular}




\section{Accuracy and Precision}

The accuracy and precision were evaluated using intraday and interday recovery experiments with three different samples with concentrations within the linearity range $(18,23$ and $30 \mathrm{mmol} \mathrm{L}^{-1}$ ). For each concentration, six replicates were prepared and injected, and the recovery and RSD were determined, representing the accuracy and precision, respectively. The procedure was repeated on two different days for interday testing ( $c f$. SI for detailed analysis procedure and all data). The data are summarized in Table 3.

The precision tests of the method showed intraday RSD values of 6-7\% for the Bobbitt salt and 6-8\% for the TMATEMPO oxoammonium cation. Although the variations are rather high, they are acceptable for the analysis of highly reactive species with a completely newly developed method. We would link the high uncertainties to variations during the derivatization process and, although reduced, the still existing instability of the analytes. In comparison, the interday precision values of the Bobbitt salt (1-3\%) and of the TMATEMPO oxoammonium cation (2-3\%) are comparable to currently applied techniques for HPLC determination. The data for the TEMPOL oxoammonium cation revealed, in contrast, much higher variations of $16 \%$, suggesting that the derivatization and analysis protocol is not suitable for this specific compound. A finding that is also confirmed by the recovery rates of 192-207\% (intraday) and 165-175\% (interday), with no clear correlation between concentration and deviation. This can be assigned to a possible oxidation of the hydroxy group in 4-position to the corresponding ketone, which can lead to the observed deviations [35].

The TMA-TEMPO oxoammonium cation also revealed high deviations of the recovery rates. In this case, an indirect linear dependency on the concentrations was found. Nevertheless, the received recovery values (121-142\% intraday and $122-143 \%$ interday) are much too high. This might be caused by a demanding calibration because of the lack of commercially available reference substances. The consequent need of the preparation of the $\mathrm{OC}$ via electrochemical oxidation of the TMA-TEMPO radical utilizing a redox flow cell suffers from technical problems like variable concentrations due to osmotic pressure differences [36-40]. To further optimize the method for the TMA-TEMPO system, these problems have to be overcome during future studies. However, the validation parameters suggest the possibility for quantitative analysis of TMA-TEMPO oxoammonium cation with this protocol.

In contrast, the results of the recovery study for the Bobbitt salt with 101-105\% intraday- and 101-106\% interday confirm the accuracy of the method for this analyte.

\section{Sample Analysis}

To further explore the applicability of the method, samples containing one type of $\mathrm{OC}$ and its corresponding radical were prepared and analyzed. For this purpose, $0.1 \mathrm{M}$ solutions of the oxoammonium cation and $0.1 \mathrm{M}$ solutions of the corresponding radical were used to produce samples with total concentrations of $35 \mathrm{mmol} \mathrm{L}^{-1}$ and $\mathrm{OC}$ ratios of 80 , 65 , and $50 \%$, respectively. The samples were prepared like described above. For each mixture, six samples were prepared and injected once in the HPLC-System. The recovery

Table 4 Data of the recovery studies for samples of the three different oxoammonium cations mixed with their corresponding radicals

\begin{tabular}{lllr}
\hline & $\begin{array}{l}\text { Concentra- } \\
\text { tion OC/radical } \\
{\left[\mathrm{mmol} \mathrm{L}^{-1}\right]}\end{array}$ & Recovery rate [\%] & RSD [\%] \\
\hline Bobbitt salt & $28 / 7$ & 101.99 & 2.95 \\
& $22.75 / 12.25$ & 109.50 & 2.54 \\
TMA-TEMPO OC & $28 / 7$ & 115.89 & 6.18 \\
& $22.75 / 12.25$ & 113.24 & 11.25 \\
TEMPOL OC & $17.5 / 17.5$ & 152.72 & 4.83 \\
& $28 / 7$ & 202.93 & 5.82 \\
& $22.75 / 12.25$ & 209.90 & 2.97 \\
& $17.5 / 17.5$ & 225.15 & 3.82 \\
\hline
\end{tabular}

Table 3 Data of the intraday (day one) and interday recovery experiments for accuracy and precision determination

\begin{tabular}{|c|c|c|c|c|c|}
\hline & \multirow{2}{*}{$\begin{array}{l}\text { Concentration } \\
\left(\mathrm{mmol} \mathrm{L}^{-1}\right)\end{array}$} & \multicolumn{2}{|l|}{ Intraday } & \multicolumn{2}{|l|}{ Interday } \\
\hline & & Recovery [\%] & $\operatorname{RSD}[\%]$ & Recovery [\%] & $\operatorname{RSD}[\%]$ \\
\hline \multirow[t]{3}{*}{ Bobbitt salt } & 30 & 101 & 6 & 101 & 3 \\
\hline & 23 & 104 & 6 & 105 & 1 \\
\hline & 18 & 105 & 7 & 106 & 2 \\
\hline \multirow[t]{3}{*}{ TMA-TEMPO OC } & 30 & 121 & 8 & 122 & 2 \\
\hline & 23 & 135 & 6 & 131 & 3 \\
\hline & 18 & 142 & 8 & 143 & 3 \\
\hline \multirow[t]{3}{*}{ TEMPOL OC } & 30 & 192 & 11 & 165 & 14 \\
\hline & 23 & 206 & 4 & 175 & 16 \\
\hline & 18 & 207 & 7 & 175 & 16 \\
\hline
\end{tabular}


rates were determined using the calibration curve and are shown in Table 4.

The data revealed the same trend of deviations as described for the inter- and intraday recovery experiments but with slightly higher recovery rates for all three systems.

This suggests that an increasing amount of radicals interferes with the accuracy of the method, but the effect only becomes significant for radical concentrations higher than $30 \%$. The problem of generally higher recovery rates of analyte in the presence of high radical amounts can be assigned to the possible reaction of the radical with allylic and benzylic substrates to alkoxyamines with similar structures to the analyte, in an NMP like manner [41, 42].

We concluded that the method can be in principle used for the quantitative analysis of oxoammonium cations even in the presence of a high amount of their corresponding radical, but the suitability for a certain substance has to been checked. The unsuitability of the method for the TEMPOL oxoammonium cation due to the possible oxidation of the 4-hydroxy group is confirmed [35].

\section{Conclusion}

We developed the first derivatization-based method for the HPLC determination of highly reactive oxoammonium cations. For this purpose, a 1,2-electropilic addition of oxoammonium cations to activated double bonds was used, as described by Takata et al. [27] Based on the latter, a determination protocol was developed and applied to three different cations, which act as model substances for oxidation catalysts, battery materials and pharmaceuticals. While the derivatized analytes are stable under auto-sampler conditions, with a very low decay rate of $0.5-1.0 \% \mathrm{~d}^{-1}$ the method suffers from the lack of commercially available reference standards. Consequently, standards have to be selfsynthesized utilizing electrochemical oxidation in redox flow cells. The consequent deviations in concentration due to osmotic processes makes the calibration error-prone. Nevertheless, the derivatization protocol and the HPLC determination method were validated according to the ICH and USP guidelines. Furthermore, we showed that the protocol can be used even for samples with high radical concentrations of up to $30 \%$, rendering the method suitable for the qualitative and quantitative determination of a broad range of oxoammonium cations.

Supplementary Information The online version contains supplementary material available at https://doi.org/10.1007/s10337-021-04084-1.

Acknowledgements We want to thank Friederike Pielenz and Bärbel Rambach for the NMR measurements. Furthermore, we want to thank Dr. Christian Friebe for the helpful discussions and comments.
Author contributions PR and RB designed the study. KS, RB, NF and $\mathrm{PR}$ performed the experiments. The first draft of the manuscript was written by PR. MDH and USS supervised and acquired the financial support for the project. All authors discussed the results and contributed to the final manuscript.

Funding Open Access funding enabled and organized by Projekt DEAL. We acknowledge the Thüringer Aufbaubank (TAB), the European Social Fund (ESF), the Thuringian Ministry of Economic Affairs, Science and Digital Society (TMWWdG) for financial support. The study was co-financed by the state of Thuringia (2015 FGI 0021) with means of the EU in the framework of the EFRE program.

Availability of data and materials During the experiments are no other data produced which are not included in the text or supplementary information.

Code availability Not applicable.

\section{Declarations}

Conflict of interest The authors declare no conflict of interest.

Open Access This article is licensed under a Creative Commons Attribution 4.0 International License, which permits use, sharing, adaptation, distribution and reproduction in any medium or format, as long as you give appropriate credit to the original author(s) and the source, provide a link to the Creative Commons licence, and indicate if changes were made. The images or other third party material in this article are included in the article's Creative Commons licence, unless indicated otherwise in a credit line to the material. If material is not included in the article's Creative Commons licence and your intended use is not permitted by statutory regulation or exceeds the permitted use, you will need to obtain permission directly from the copyright holder. To view a copy of this licence, visit http://creativecommons.org/licenses/by/4.0/.

\section{References}

1. Finklea HO, Madhiri N (2008) Reorganization energies of TEMPO/TEMPO in water. J Electroanal Chem 621:129-133. https://doi.org/10.1016/j.jelechem.2007.07.026

2. Bobbitt JM, Brückner C, Merbouh N (2010) Oxoammonium- and nitroxide-catalyzed oxidations of alcohols. Org React 74:27772830. https://doi.org/10.1002/0471264180.or074.02

3. Beejapur HA, Zhang Q, Hu KC, Zhu L, Wang JL, Ye ZB (2019) TEMPO in chemical transformations: from homogeneous to heterogeneous. ACS Catal 9:2777-2830. https://doi.org/10.1021/ acscatal.8b05001

4. Silva ABV, Silva ED, dos Santos AA, Princival JL (2020) A sustainable access to ynones through laccase/TEMPO-catalyzed metal- and halogen-free aerobic oxidation of propargylic alcohols in aqueous medium. Catal Commun 137:105946-105952. https:// doi.org/10.1016/j.catcom.2020.105946

5. Denlinger KL, Carr P, Waddell DC, Mack J (2020) A recyclable, metal-free mechanochemical approach for the oxidation of alcohols to carboxylic acids. Molecules 25:364-374. https://doi.org/ 10.3390/molecules 25020364

6. Pierre G, Punta C, Delattre C, Melone L, Dubessay P, Fiorati A, Pastori N, Galante YM, Michaud P (2017) TEMPO-mediated oxidation of polysaccharides: an ongoing story. Carbohydr Polym 165:71-85. https://doi.org/10.1016/j.carbpol.2017.02.028 
7. Kwabi DG, Ji Y, Aziz MJ (2020) Electrolyte lifetime in aqueous organic redox flow batteries: a critical review. Chem Rev 120:6467-6489. https://doi.org/10.1021/acs.chemrev.9b00599

8. Janoschka T, Martin N, Hager MD, Schubert US (2016) An aqueous redox-flow battery with high capacity and power: the TEMPTMA/MV system. Angew Chem Int Ed 55:14427-14430. https://doi.org/10.1002/anie.201606472

9. Winsberg J, Stolze C, Schwenke A, Muench S, Hager MD, Schubert US (2017) Aqueous 2,2,6,6-tetramethylpiperidine-n-oxyl catholytes for a high-capacity and high current density oxygeninsensitive hybrid-flow battery. ACS Energy Lett 2:411-416. https://doi.org/10.1021/acsenergylett.6b00655

10. Wilcox CS, Pearlman A (2008) Chemistry and antihypertensive effects of tempol and other nitroxides. Pharmacol Rev 60:418469. https://doi.org/10.1124/pr.108.000240

11. Zarling JA, Brunt VE, Vallerga AK, Li W, Tao A, Zarling DA, Minson CT (2015) Nitroxide pharmaceutical development for agerelated degeneration and disease. Front Genet 6:325-334. https:// doi.org/10.3389/fgene.2015.00325

12. Hall ED, Vaishnav RA, Mustafa AG (2010) Antioxidant therapies for traumatic brain injury. Neurotherapeutics 7:51-61. https://doi. org/10.1016/j.nurt.2009.10.021

13. Hagemann T, Strumpf M, Schröter E, Stolze C, Grube M, Nischang I, Hager MD, Schubert US (2019) (2,2,6,6-tetramethylpiperidin-1-yl)oxyl-containing zwitterionic polymer as catholyte species for high-capacity aqueous polymer redox flow batteries. Chem Mater 31:7987-7999. https://doi.org/10.1021/acs.chemm ater.9b02201

14. Duan TT, Zhai TR, Liu HH, Yan ZL, Zhao Y, Feng L, Ma C (2016) One-pot three-component synthesis of quinazolines via a copper-catalysed oxidative amination reaction. Org Biomol Chem 14:6561-6567. https://doi.org/10.1039/c6ob00625f

15. Gong M, Kim JK, Zhao XL, Li YB, Zhang JY, Huang MM, Wu YJ (2019) Visible-light-induced alpha-oxyamination of 1,3-dicarbonyls with TEMPO via a photo(electro)catalytic process applying a DSSC anode or in a DSSC system. Green Chem 21:3615-3620. https://doi.org/10.1039/c9gc01154d

16. Ma Y, Loyns C, Price P, Chechik V (2011) Thermal decay of TEMPO in acidic media via an N-oxoammonium salt intermediate. Org Biomol Chem 9:5573-5578. https://doi.org/10.1039/ c1ob05475a

17. Bobbitt JM, Eddy NA, Cady CX, Jin J, Gascon JA, GelpiDominguez S, Zakrzewski J, Morton MD (2017) Preparation of some homologous TEMPO nitroxides and oxoammonium salts; notes on the NMR spectroscopy of nitroxide free radicals; observed radical nature of oxoammonium salt solutions containing trace amounts of corresponding nitroxides in an equilibrium relationship. J Org Chem 82:9279-9290. https://doi.org/10.1021/ acs.joc. $7 \mathrm{~b} 00846$

18. Mazur M (2006) A dozen useful tips on how to minimise the influence of sources of error in quantitative electron paramagnetic resonance (EPR) spectroscopy-a review. Anal Chim Acta 561:1-15. https://doi.org/10.1016/j.aca.2006.01.006

19. Jiao Y, Tang B, Zhang Y, Xu JF, Wang Z, Zhang X (2018) Highly efficient supramolecular catalysis by endowing the reaction intermediate with adaptive reactivity. Angew Chem Int Ed 57:60776081. https://doi.org/10.1002/anie.201713351

20. Haidasz EA, Meng D, Amorati R, Baschieri A, Ingold KU, Valgimigli L, Pratt DA (2016) Acid is key to the radical-trapping antioxidant activity of nitroxides. J Am Chem Soc 138:5290-5298. https://doi.org/10.1021/jacs.6b00677

21. Grampp G, Rasmussen K (2002) Solvent dynamical effects on the electron self-exchange rate of the TEMPO /TEMPO+couple (TEMPO = 2,2,6,6-tetramethyl-1-piperidinyloxy radical): Part I. ESR-linebroadening measurements at $\mathrm{T}=298 \mathrm{~K}$. Phys Chem Chem Phys 4:5546-5549. https://doi.org/10.1039/b206313a
22. Karimi B, Vahdati S, Vali H (2016) Synergistic catalysis within TEMPO-functionalized periodic mesoporous organosilica with bridge imidazolium groups in the aerobic oxidation of alcohols. RSC Adv 6:63717-63723. https://doi.org/10.1039/c6ra15483b

23. Vignaduzzo SE, Maggio RM, Olivieri AC (2020) Why should the pharmaceutical industry claim for the implementation of secondorder chemometric models-A critical review. J Pharm Biomed Anal 179:112965. https://doi.org/10.1016/j.jpba.2019.112965

24. Singh I, Juneja P, Kaur B, Kumar P (2013) Pharmaceutical applications of chemometric techniques. ISRN Anal Chem 2013:1-13. https://doi.org/10.1155/2013/795178

25. Manley M (2014) Near-infrared spectroscopy and hyperspectral imaging: non-destructive analysis of biological materials. Chem Soc Rev 43:8200-8214. https://doi.org/10.1039/c4cs00062e

26. Smith CD, Bartley JP, Bottle SE, Micallef AS, Reid DA (2000) Electrospray ionization mass spectrometry of stable nitroxide free radicals and two isoindoline nitroxide dimers. J Mass Spectrom 35:607-611. https://doi.org/10.1002/(sici)1096-9888(200005) 35:5\%3c607::Aid-jms967\%3e3.0.Co;2-7

27. Takata T, Tsujino Y, Nakanishi S, Nakamura K, Yoshida E, Endo $\mathrm{T}$ (1999) Electrophilic 1,2-addition of oxoammonium salts to olefins. Chem Lett 28:937-938. https://doi.org/10.1246/cl.1999.937

28. Bobbitt JM (1998) Oxoammonium salts. 6.14-acetylamino2,2,6,6-tetramethylpiperidine-1-oxoammonium perchlorate: a stable and convenient reagent for the oxidation of alcohols. Silica gel catalysis. J Org Chem 63:9367-9374. https://doi.org/10.1021/ jo981322c

29. Golubev VA, Zhdanov RI, Gida VM, Rozantsev EG (1971) Reaction of iminoxyl radicals with some mineral acids. Bull Acad Sci USSR, Div Chem Sci 20:768-770. https://doi.org/10.1007/bf008 53921

30. Kelly CB, Mercadante MA, Hamlin TA, Fletcher MH, Leadbeater NE (2012) Oxidation of alpha-trifluoromethyl alcohols using a recyclable oxoammonium salt. J Org Chem 77:8131-8141. https:// doi.org/10.1021/jo301477s

31. Bobbitt J, Tilley LJ, Murray S, Camire C, Eddy N (2012) A revised preparation of (4-acetamido-2,2,6,6-tetramethylpiperidin1-yl)oxyl and 4-acetamido-2,2,6,6-tetramethyl-1-oxopiperidinium tetrafluoroborate: reagents for stoichiometric oxidations of alcohols. Synthesis 45:326-329. https://doi.org/10.1055/s-0032-13178 61

32. Borman P, Elder D (2017) Q2(R1) validation of analytical procedures. In: Teasdale A, Elder D, Nims RW (eds) ICH quality guidelines: an implementation guide. Wiley, Hoboken, USA, pp 127-166. https://doi.org/10.1002/9781118971147.ch5

33. United States Pharmacopeia (2014) United States pharmacopeial convention. United States Pharmacopeia, Rockville

34. Evaluation CfD, Research a (1994) Reviewer guidance, validation of chromatographic methods

35. Marshall DL, Christian ML, Gryn'ova G, Coote ML, Barker PJ, Blanksby SJ (2011) Oxidation of 4-substituted TEMPO derivatives reveals modifications at the 1- and 4-positions. Org Biomol Chem 9:4936-4947. https://doi.org/10.1039/c1ob05037k

36. Hagemann T, Winsberg J, Grube M, Nischang I, Janoschka T, Martin N, Hager MD, Schubert US (2018) An aqueous all-organic redox-flow battery employing a (2,2,6,6-tetramethylpiperidin1 -yl)oxyl-containing polymer as catholyte and dimethyl viologen dichloride as anolyte. J Power Sources 378:546-554. https://doi. org/10.1016/j.jpowsour.2017.09.007

37. Yan L, Li D, Li S, Xu Z, Dong J, Jing W, Xing W (2016) Balancing osmotic pressure of electrolytes for nanoporous membrane vanadium redox flow battery with a draw solute. ACS Appl Mater Interfaces 8:35289-35297. https://doi.org/10.1021/acsami.6b120 68

38. Prifti H, Parasuraman A, Winardi S, Lim TM, Skyllas-Kaza$\cos$ M (2012) Membranes for redox flow battery applications. 
Membranes 2:275-306. https://doi.org/10.3390/membranes2 020275

39. Li XF, Zhang HM, Mai ZS, Zhang HZ, Vankelecom I (2011) Ion exchange membranes for vanadium redox flow battery (VRB) applications. Energ Environ Sci 4:1147-1160. https://doi.org/10. 1039/c0ee00770f

40. Feng T, Wang HN, Liu YY, Zhang J, Xiang Y, Lu SF (2019) A redox flow battery with high capacity retention using 12-phosphotungstic acid/iodine mixed solution as electrolytes. J Power Sources. https://doi.org/10.1016/j.jpowsour.2019.226831

41. Babiarz JE, Cunkle GT, DeBellis AD, Eveland D, Pastor SD, Shum SP (2002) The thermal reaction of sterically hindered nitroxyl radicals with allylic and benzylic substrates: experimental and computational evidence for divergent mechanisms. J Org Chem 67:6831-6834. https://doi.org/10.1021/jo020426r

42. Vogler T, Studer A (2008) Applications of TEMPO in synthesis. Synthesis 2008:1979-1993. https://doi.org/10.1055/s-2008-10784 45

Publisher's Note Springer Nature remains neutral with regard to jurisdictional claims in published maps and institutional affiliations. 